\title{
Design of mechatronic engineering systems in digitalized traditional and additive manufacturing
}

\author{
Mikhail L. Kheifetz \\ Institute of Applied Physics of the National Academy of Sciences of Belarus, \\ 16, Akademicheskaya St., Minsk, Belarus \\ mlk-z@mail.ru
}

\begin{abstract}
The paper presents the analysis of the steps and stages of designing process equipment for traditional manufacturing. The features of building process equipment using energy flows and consumables are studied. Structural synthesis of mechatronic systems in digitalized manufacturing make it possible to add new stages to the process of creating process equipment for both traditional automated subtractive and new additive manufacturing. The processes of manufacturing parts without forming equipment described by the algorithms according to the proposed structural diagram of connections provide an opportunity to analyze the existing equipment and develop new equipment for laminate synthesis of products.

The paper illustrates the use of methods and procedures for laminate synthesis and fabrication of parts from composite materials using process equipment based on the application of energy flows and material components for new additive and traditional subtractive manufacturing. Also, methods and diagrams for automation and computer-aided process control over product manufacturing are shown.
\end{abstract}

Keywords: process equipment; additive and subtractive manufacturing; laminate synthesis; product fabrication.

For citation: Kheifetz ML. Design of mechatronic engineering systems in digitalized traditional and additive manufacturing. Journal of Advanced Materials and Technologies. 2021;6(1):18-29. DOI: 10.17277/jamt.2021.01.pp.018-029

\section{Проектирование мехатронных технологических комплексов при цифровизации традиционного и аддитивного производства}

\author{
М. Л. Хейфец \\ ГНУ Институт прикладной физики Национальной академии наук Беларуси, \\ ул. Академическая, 16, Минск, Республика Беларусь \\ mlk-z@mail.ru
}

\begin{abstract}
Аннотация: Проведен анализ стадий и этапов проектирования технологического оборудования для традиционного производства, изучены особенности формирования технологического оборудования, использующего потоки энергии и расходных материалов. Структурный синтез мехатронных комплексов в цифровизированном производстве позволил дополнить новыми этапами процесс создания технологического оборудования как для традиционного автоматизированного субтрактивного, так и нового аддитивного производства. Описанные алгоритмами по предложенной структурной диаграмме связей процессы изготовления деталей без формообразующей оснастки, предоставляют возможность анализировать существующее и разрабатывать новое оборудование для послойного синтеза изделий.

Показано, как при проектировании технологического оборудования для его использования в новом аддитивном и традиционном субтрактивном производстве, применяются методы и схемы послойного синтеза и формообразования деталей из композиционных материалов, построенные на использовании различных потоков энергии и компонентов материала, а также методы и схемы автоматизации и компьютерного управления процессами производства изделий.
\end{abstract}

Ключевые слова: технологическое оборудование; аддитивное и субтрактивное производство; послойный синтез; формообразование изделий.

Для цитирования: Kheifetz ML. Design of mechatronic engineering systems in digitalized traditional and additive manufacturing. Journal of Advanced Materials and Technologies. 2021;6(1):18-29. DOI: 10.17277/jamt.2021.01.pp.018-029 


\section{Introduction}

When designing process equipment for digitalization of both traditional subtractive and new additive manufacturing, it is possible to apply the existing methods and new ones for fabrication and laminate synthesis of products, as well as their automation and computerization, intensive modification of materials and surfaces with concentrated and distributed flows of energy and components of substances [1-5].

Traditionally, the initial data for the design of process equipment contains the technical design specification for a specific customer, including $[6,7]$ :

(1) the data on materials and finished products; (2) the equipment performance; (3) the nature and type of manufacturing; (4) the level of automation and integration into modern high-tech industry.

However, this information is not sufficient when designing process equipment using distributed fields and concentrated flows of energy and components of substances [1-3] for computer-aided subtractive and additive manufacturing $[4,5,8]$. This is due to the fact that both for traditional types of subtractive $[9,10]$ and new types of additive $[11,12]$ manufacturing, which consist in layer-by-layer buildup of the surface of products, it is required to additionally consider the supply and distribution of energy and material [13, 14].

In this regard, the aim of the paper is to develop the existing methodology for the design of process equipment facilities with computer-aided control of processes, both for traditional methods of combined electro-physicochemical fabrication of parts, and for new methods of laminate synthesis of products from composite materials in additive manufacturing.

\section{The analysis of the steps and stages in the design of process equipment for traditional manufacturing}

The design process, including structural synthesis and parametric optimization of equipment used in traditional subtractive and new additive manufacturing covers various methods and procedures for formation and synthesis of products, as well as their automation and computerization.

\subsection{Structural synthesis}

The sequence of design of process equipment for traditional-type manufacturing includes 8 enlarged stages based on the design diagrams (Fig. 1) $[4,6,7]$ :

1. Layout and selection of the kinematic diagram (see Fig. 1, $a$ ).

2. Modular design for a limited set of units and assemblies $[15,16]$.

3. Calculations of static elastic displacements, the selection of the diagram and strength calculations (see Fig. 1, b).

4. Dynamic calculations of the stability of system movements and static deviations of elements, the selection of the diagram and dynamic calculations (see Fig. 1, c).

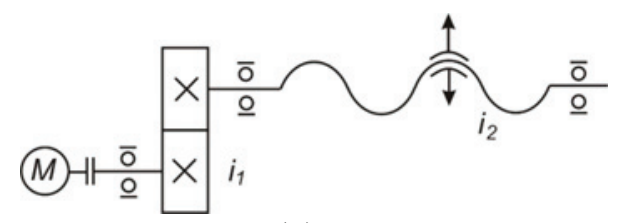

(a)

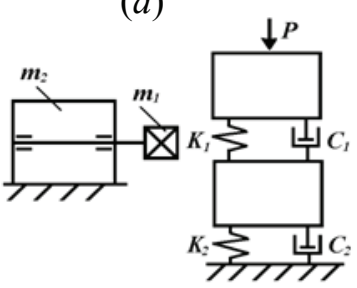

(c)



(e)



(b)

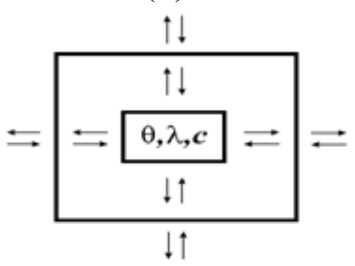

(d)

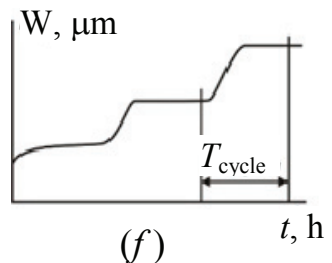

$(f)$

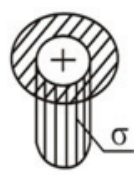

Fig. 1. Diagrams for the main systems of process equipment:

$a$ - kinematic; $b$ - strength; $c$-dynamic; $d$ - thermodynamic; $e$ - contact-and-friction; $f$ - wear-and-reliability 
5. Thermal calculations, the selection of thermodynamic scheme and calculation of temperatures (see Fig. $1, d$ ).

6. Precision calculations, including the determination of the accuracy of geometric and kinematic connections (see Fig. 1, a), taking into account deformations: general (see Fig. 1, $b, c$ ), thermal (see Fig. 1, d) and contact-and-friction (see Fig. 1,e).

7. Calculations of reliability and durability, including determination of the reliability of units and assemblies (see Fig. 1, $a-c$ ), taking into account thermal and deformation processes (see Fig. 1, $d, e$ ) friction and wear (see Fig. 1, f), and in conclusion, the economic justification of the resource.

8. The analysis of the human-machine system, which also includes occupational health and safety requirements [6].

Further, by stages for process equipment, the calculations are made for the main systems: (1) bearing systems; (2) guiding movements; (3) drives of movements and others.

The design and calculation of the main systems is carried out according to the technical requirements for mechanical units, process equipment and automation equipment; lubrication systems, electrical equipment and programmable systems; diagnostic systems, taking into account safety, ergonomics and manufacturability of the machine $[4,6,7]$.

For this, system diagrams are constructed, taking into account the limiting sets of units and assemblies: (1) kinematic (see Fig. 1, a); (2) process modules $[15,16]$; (3) strength (see Fig. 1, b); (4) dynamic (see Fig. 1, c); (5) thermodynamic (see Fig. 1, d); (6) contact-and-friction (see Fig. 1, e); (7) wear-andreliability (see Fig. 1,f); (8) the man-machine system as a whole [6].

\subsection{Parametric optimization}

Having completed the structural synthesis, parametric optimization is carried out $[17,18]$; it determines the main parameters of process equipment systems. Determination of the parameters of the kinematic module is often associated with the optimization of its structure, in particular, due to the rational placement of adjustment elements in it [19]. This task relates to structural-parametric synthesis and optimization, as a result of which a rational structure of the object is formed and the values of the parameters of its elements are found in order to satisfy the requirements of synthesis with optimization during adjustment.

Let me consider the way of solving this problem using the example of a differential mechanical module with two driving links 1 and 3, output link 6 and two adjustments $i_{x}$ and $i_{y}$ (Fig. 2), which can be used for parallel connection of two kinematic groups [19].

The kinematic connections of the modules $1 \rightarrow 2 \rightarrow \Sigma \rightarrow 5 \rightarrow 6$ and $3 \rightarrow 4 \rightarrow \Sigma \rightarrow 5 \rightarrow 6$ have a common area 5-6 and autonomous areas $1-2$ and 3-4 connected to it through a summing mechanism $\Sigma$. The adjustment element $i_{x}$ of the first kinematic group can be located either in its autonomous area 1-2 (see Fig. 2, a) or in the common area 5-6 (see Fig. 2, b). Similarly, the adjusting element $i_{y}$ of the second kinematic group can also be located either in its autonomous area 3-4 or in the common area 5-6. Therefore, let me analyze various options for the placement of adjustment elements $i_{x}$ и $i_{y}$ [19]. If they are in the indicated autonomous areas of internal connections from the beginning, the structure of these connections can be represented as follows:

$$
\begin{aligned}
\alpha \rightarrow 1 \rightarrow i_{x} & \rightarrow 2 \rightarrow \underset{\uparrow}{\Sigma} \rightarrow 5 \rightarrow 6 \rightarrow \varphi+\theta \\
\beta & \rightarrow 3 \rightarrow i_{y} \rightarrow 4 .
\end{aligned}
$$

When one of the adjustment elements is in the common area 5-6, and if the element $i_{x}$ is located in it, the following structure of the module's internal links is obtained:

$$
\begin{aligned}
\alpha \rightarrow 1 & \rightarrow 2 \rightarrow \underset{\uparrow}{\sum} \rightarrow 5 \rightarrow i_{x} \rightarrow 6 \rightarrow \varphi+\theta \\
\beta \rightarrow 3 & \rightarrow i_{y} \rightarrow 4 .
\end{aligned}
$$

When placing the adjustment elements according to the first option, it is necessary to reconfigure both adjustment elements, which is associated with an increase in labor intensity; it is also often impossible

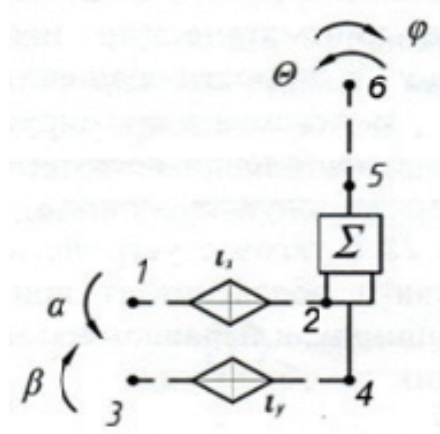

(a)

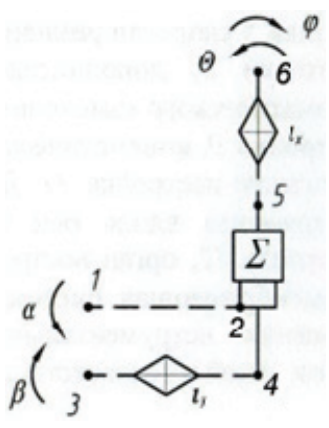

(b)
Fig. 2. Kinematic diagrams of the connection of the internal bonds of links $1-6$ of the kinematic chain with the arrangement of the adjustment elements $i_{x}$ and $i_{y}$ in autonomous areas $(a)$ and in a common area $(b)$ 
to ensure the same gear ratio values of the adjustment element and, therefore, the identity of the processed products for a certain parameter $x$. Since in the second option the value of $i_{y}$ does not depend on the parameter $x$, then when proceeding to processing a product with a different value of this parameter, it is required to change the gear ratio of the element $i_{x}$.

Each option of the structure of the kinematic module is characterized by certain values of the parameters of the adjustment elements, which have a different effect on the functional properties of the designed object, in this case, the forming system of the process equipment [19]. Thus, the synthesis of the designed object is reduced to analyzing possible options of its structure and selecting the option with rational values of the adjusted parameters.

\subsection{Supply and distribution of material and energy}

It should be noted that when creating process equipment for automated subtractive and additive manufacturing, using concentrated and distributed flows of energy and material (Fig. 3) [1-3], it is not sufficient to have enlarged 8 stages involving the selection of system parameters, the procedures and the corresponding diagrams $[4,5,8]$. This is due to the fact that for traditional types of subtractive manufacturing and new types of additive manufacturing, consisting in layer-by-layer build-up of the surface of products, at the subsequent additionally introduced design stages, it is required to consider procedures and determine the parameters of process equipment modules describing the supply and distribution of material and energy [13, 14].

\section{Design of process equipment using energy flows}

The technologies widely used in manufacturing lead to the conclusion that the use of equipment for building-up layers and forming the surfaces of products using various combinations of energy and material flows is quite promising (see Fig. 3). This, in turn, poses the problem of distributing the components of the material and energy sources not only along a given contour or surface, but also in depth from the surface of the product, as well as taking into account the nature of the pulses of material and energy supply $[4,5,8,13,14]$.

\subsection{Heat and mass transfer criteria}

The problems of distribution of material and energy flows help to solve the criteria of heat and mass transfer, which establish the sequence of structure formation in the processed material and on the formed surface with an increase in the power of impacts $[4,8,13,20]$ :

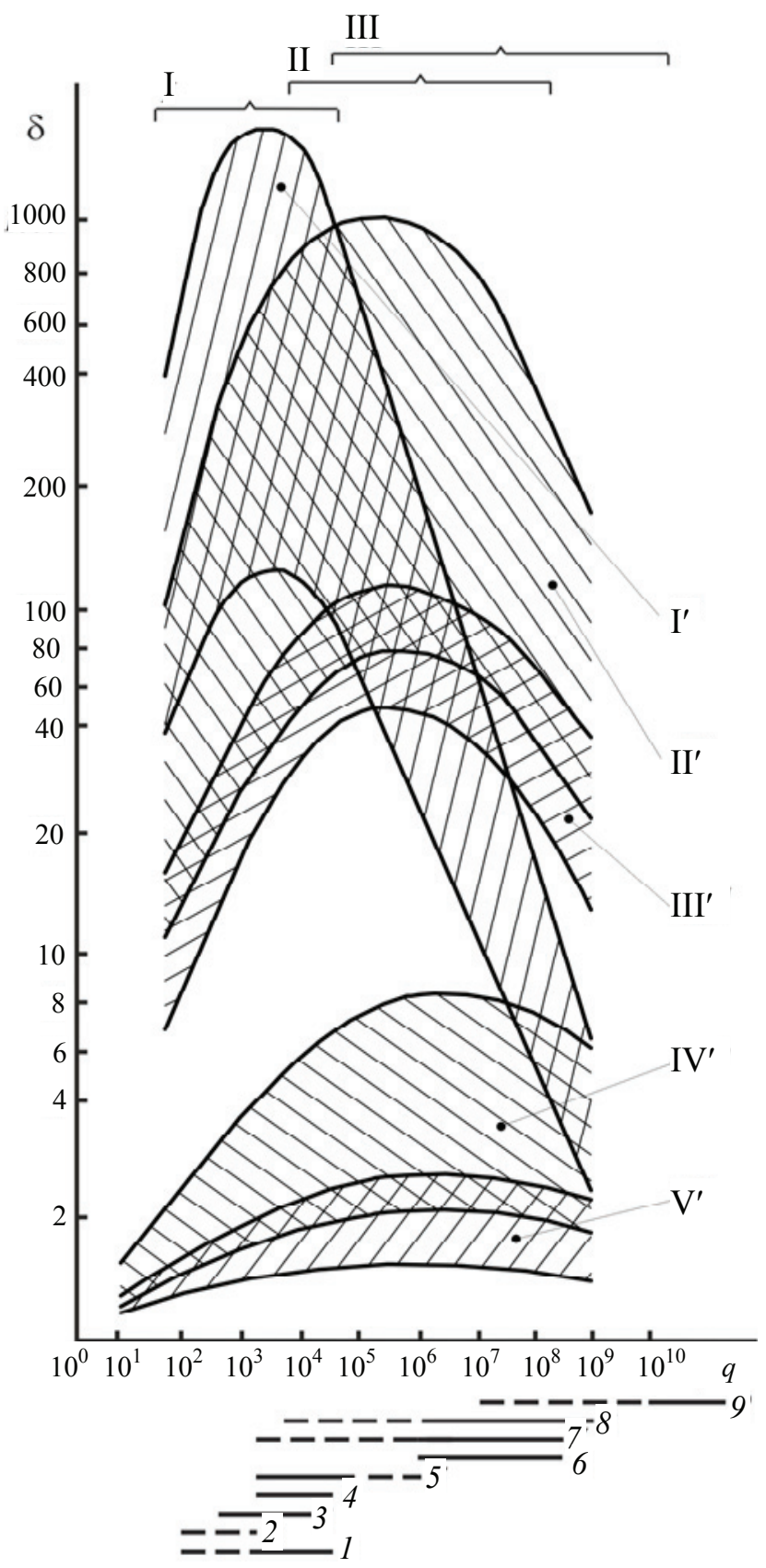

Fig. 3. Distribution of trestment methods according to the accuracy of surface formation:

$\mathrm{I}^{\prime}$ - material separation; II' - coating; III' - heat treatment; $I^{\prime}$ - cutting with a tool; $\mathrm{V}^{\prime}$ - deformation; depending on the level of concentration in the zones of energy release: I - surface-distributed; II - set of localized; III - focused; for sources: 1 - induction heating; 2 - gas flame; 3 - plasma arc; 4 - electric contact heating; 5 - welding arc; 6 - spark discharge; 7 - electron, ion beam; 8 - continuous laser; 9 - pulse-periodic laser 


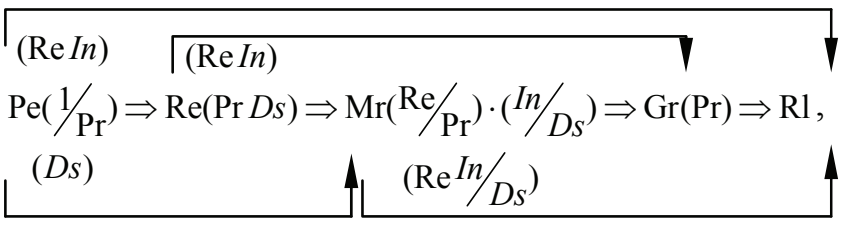

in which $\mathrm{Pe}=v t / \omega$ is the Peclet criterion; $\operatorname{Pr}=v / \omega$ is the Prandtl criterion; $\operatorname{Re}=v t / v$ is the Reynolds criterion; In $=\beta g \nabla T^{t^{2}} / \mathrm{v}^{2}$ is the ratio of buoyancy to inertial force; $D s=\sigma_{k} \nabla T^{t} /(v \rho / v)$ is the ratio of the forces of capillarity and viscosity; $\mathrm{Mr}=\sigma_{k} \nabla T^{t^{2}} /(\rho \omega v)$ is the Marangoni test; $\mathrm{Gr}=\beta g \nabla T^{t^{4}} / \mathrm{v}^{2} \quad$ is the Grashof test; $\mathrm{Rl}=\beta g \nabla T^{t^{4}} /(\omega \nu)$ is the Rayleigh criterion; where $t$ is the characteristic dimension; $\omega$ is the coefficient of thermal diffusivity; $v$ is the velocity; $v$ is the coefficient of kinematic viscosity; $\beta$ is the coefficient of volumetric expansion; $g$ is the acceleration of gravity; $T$ is the absolute temperature; $\sigma_{k}$ is the thermocapillarity coefficient; $\rho$ is the density of the process medium.

\subsection{Electrical power criteria}

The criteria characterizing energy flows during electro-physical-chemical processing have a significant impact on the sequence of spatial phenomena and help to control the formation of the properties of the processed material $[4,8,13,20]$ :

$$
\operatorname{Sm}(E m / S e) \Rightarrow S i ; \quad \operatorname{Mr}(E k) \Rightarrow E(T k / E k) \Rightarrow \mathrm{R} 1,
$$

in which $S m=I B /\left(v^{2} \rho t\right)$ is the magnetic impact criterion; $E m=v E_{1} /\left(H^{\prime} B\right)$ is the ratio of the flow velocity to its heat content and the electric field strength to its magnetic induction; $S e=E_{1} t^{2} /(I R)$ is the electric field intensity criterion; $S i=I^{2} R /\left(v \rho H^{\prime} t^{3}\right) \quad$ is the energy criterion; $E k=\varepsilon \gamma^{2} \nabla T / \sigma_{k}$ is the ratio of thermoelectric and capillary forces; $E=\varepsilon \gamma^{2} \nabla T^{2} t^{2} /(\rho \omega v)$ is the thermoelectric criterion; $T k=\rho \beta g t^{2} / \sigma_{k}$ is the ratio of buoyancy to capillary lift;

where $I$ is the current strength; $B$ is the magnetic induction; $H^{\prime}$ is the flow enthalpy; $R$ is the electrical resistance; $\varepsilon$ is dielectric factor; $\gamma$ is the thermoelectromotive force coefficient $E_{1}$ is the electric field strength.
The use of sequences of transfer criteria (1) and (2) to analyze the processes of formation of structures and phases of a material greatly reduces the volume of experimental studies of the technology of formation of a surface layer with combined methods of thermomechanical and electro-physical-chemical treatment $[4,8,13,20]$.

\subsection{Feedback in the process system}

When unstable structures of surface layers are formed, it is advisable to measure the turbulence of flows and flows of the treated material, using the Reynolds criterion $\mathrm{Re}=v t / v$, and describe the waviness and roughness of the forming surface relief $R$. The thickness of the formed layer $t$ determines the increase or decrease in its mass $Q$, and taking into account the continuity or porosity of the laminate material or coatings change their relative hardness $H_{\varepsilon}=\Delta H / H$. Therefore, the layer thickness $t$ is proportional to the expression $Q /\left(1-H_{\varepsilon}\right)[3,4,8,20]$.

As a result, when controlling energy flows, it is advisable to use ratios proportional to the transfer criteria to optimize the geometric characteristics of the surface relief:

$$
R \approx \frac{\mathrm{v}_{S}\left[Q /\left(1-H_{\varepsilon}\right)\right]}{(B / I) \cdot(\mathrm{v} / S)}=\frac{\mathrm{v}_{S} S I Q}{\mathrm{v} B\left(1-H_{\varepsilon}\right)},
$$

and to optimize the physical and mechanical parameters of the relative hardening of the material of the surface layer from relation (3) we obtain:

$$
H_{\varepsilon} \approx 1-\frac{\mathrm{v}_{S} S I Q}{\mathrm{v} B R},
$$

where $v_{S}$ is the total velocity of the main $v$ and additional $S$ of motions.

Relations (3) and (4) show a positive feedback of the relief $R$ and a negative feedback of hardening $H_{\varepsilon}$ with the treatment performance $v_{S} Q$, as well as with the adjustable components of the kinematic characteristics of the equipment $(S / \mathrm{v})$ and the power of the energy source $(I / B)[3,4,8,20]$. The analysis of relations (3) and (4) allows finding the basic principles of organizing feedback in an open process system.

In the case when, first of all, it is necessary to form the surface (3), and then to strengthen it (4), as, for example, during deformation and cutting, a positive feedback is created in the process system under thermomechanical impacts. Excessive degrees of freedom of the tool and the process environment, suppressing the scattering of energy and substance 
flows in the shape-changeable allowance, create strengthening structures in the surface layer and increase the processing efficiency $[3,4,8,14]$. In the case when first it is required to strengthen (4) and then to form the surface relief (3), as, for example, when applying coatings, a negative feedback is organized in the process system under electrophysical-chemical influences. Additional impacts by energy sources and substances, forming strengthening structures in the surface layer, do not allow the development of process instability during the formation of the surface relief and, when it is stabilized, do not allow to increase the treatment performance [3, 4, 8, 14].

Taking into account the contours of direct and feedback links in the process system, it is also required to study numerical control schemes and consider the complex of process equipment as a mechatronic system $[1,3,4,21]$.

\section{Design of process equipment for additive manufacturing of products}

If, in the process of digitalization of production, process equipment is considered from the standpoint of computerization of manufacturing; the equipment for the implementation of additive technologies, its nodes and parts should be designed as computer peripheral devices built on the same architecture as a computer.

To designate the processes of additive manufacturing of products in the process system, the terms that have historically formed in the course of its evolution are most often used: direct manufacturing of products of complex shape - "growing" (Solid Freeform Fabrication); layer-by-layer manufacturing "synthesis" (Laminate Synthesis); rapid prototyping "prototyping" (Rapid Prototyping); the formation of three-dimensional objects - "printing" (3D Component Forming). Therefore, it is necessary to determine the relationship of the forming processes and make a distinction between the terms used [4, 5, 8, 22, 23].

\subsection{Finite state machines and the self-reproduction model}

For Solid Freeform Fabrication, self-reproduction of products by the von Neumann model [22, 23], the following machines are required: $\mathrm{C}$ is "a copier of the design plan"; $\mathrm{O}$ is "an executor of the design plan"; $\mathrm{S}$ is "a starting device" (including $\mathrm{C}$ and $\mathrm{O}$ at the appropriate time); $\mathrm{B}_{\mathrm{C}+\mathrm{O}+\mathrm{S}}$ is "a plan for building the automaton" (describing all the elements of the model). As a result, the entire automaton is

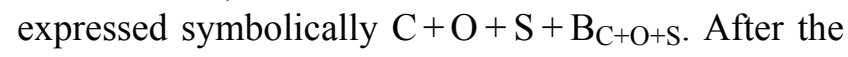

initial launch, $\mathrm{S}$ gets at its disposal the plan for buiding the automaton as a whole $\mathrm{B}_{\mathrm{C}+\mathrm{O}+\mathrm{S}}, \mathrm{C}$ copies it, and $\mathrm{O}$, in turn, follows it to build $\mathrm{C}, \mathrm{O}$ and $\mathrm{S}$.

Then, one can represent $[4,5,8,22,23]$ the launch of $\mathrm{S}$ as a direct access to the flows of matter and energy; getting the $\mathrm{B}_{\mathrm{C}+\mathrm{O}+\mathrm{S}}$ plan as selfadjustment of the reproduction program; copying of the plan by $\mathrm{C}$ as translation of the information stream; building the automaton $\mathrm{O}$ as self-organization of its structure.

The study of the production processes of parts without the use of forming equipment [4, 5, 8, 22, 23], depending on the state of aggregation of the initial material, the dimension of the flows of the forming medium and the sequence of process operations made it possible to present a set of methods for "growing" parts in the form of a structural diagram of connections (Fig. 4, a).

The structural diagram of connections is a directed closed graph and describes an automaton with a finite number of states [4, 5, 8, 22, 23]. The vertices of the graph depict the processes of fabrication of parts without forming tools and represent logical operations: translation of information, flows of matter and energy; starting and stopping an automatic cycle.

The edges of the graph reflect changes in the states $\left(1-6\right.$ and $\left.1^{\prime}, 2^{\prime}, 4^{\prime}\right)$ of the material of the process environment, and the routes provide for various combinations of changes depending on the choice of the initial process and the order of execution of subsequent processes.

Thus, different options for process routes have the form of different sequences when selected as the initial process (see Fig. 4, a):

- direct production of parts of complex shape: $1 \rightarrow 2 \rightarrow 3 ; 4 \rightarrow 3 ; 1 \rightarrow 5 ; 4 \rightarrow 2^{\prime} \rightarrow 5 ; 6$;

- layer-by-layer production: $\quad I^{\prime} \rightarrow 4 \rightarrow 3$; $2 \rightarrow 3 ; 1^{\prime} \rightarrow 6 ; 2 \rightarrow 4^{\prime} \rightarrow 6 ; 5$;

- fast prototyping: $2^{\prime} \rightarrow 1^{\prime} \rightarrow 6 ; 4^{\prime} \rightarrow 6 ; 2^{\prime} \rightarrow 5$; $4^{\prime} \rightarrow 1 \rightarrow 5 ; 3$.

Considering the replacement in the selfreproduction model of processes (direct access to the flows of matter and energy $\mathrm{S}$; self-adjustment of the

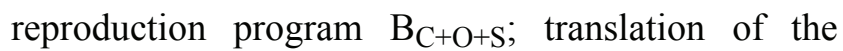
information flow $\mathrm{C}$; self-organization of the structure of the automaton $\mathrm{O}$ ) by providing them with elements of the traditional non-adaptive process system (part, tool, device, machine ), we come to the conclusion that it is impossible to create a finite automaton only when using a forming equipment, since it must exist for the manufacture of a part, and in turn, the equipment must also be made to produce it, etc. 




(a)



(b)

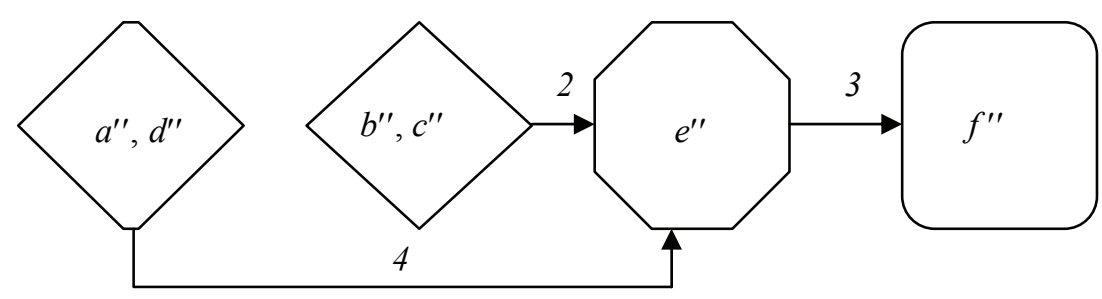

(c)

Fig. 4. Structural diagram of connections in the methods of manufacturing machine parts without forming equipment ( $a$ ), joining sheet materials $(b)$, sintering and fusing powder layers $(c)$

Thus, the algorithms proposed according to the von Neumann self-reproduction model [4, 5, 8, 22, 23] make it possible to describe the methods of manufacturing machine parts without forming equipment, and the inverse sequences, using nonadaptive tooling methods, are not representable as a finite automaton.

In accordance with the existing terms, the description of the processes of manufacturing parts without forming tools with algorithms in compliancy with the proposed structural diagram of connections provides an opportunity to analyze the existing equipment and develop new process equipment for direct solid freeform fabrication of products $[4,5,21,24]$.

Let me consider traditional additive methods of manufacturing machine parts described in the review [25] without forming tools [26-29].

\subsection{Laminate Synthesis}

The process equipment for the manufacture of parts from sheet materials [28] generally includes (Fig. 4, $a$ ) installation $a^{\prime}$, containing a laser and a scanning device for coordinating cutting and cutting of sheet blanks, manipulator $b^{\prime}$, which ensures the movement of the cut sheet contours and their stacking, press $c^{\prime}$ and oven $d^{\prime}$ for molding and volumetric sintering of the formed parts. The computer-based system $e^{\prime}$ provides control of the process equipment and optimal cutting of the sheet.

Having matched the flows of matter and energy $\mathrm{S}$ - the part formed on the press $c^{\prime}$ and in the furnace $d^{\prime}$, the prototyping program $\mathrm{B}-$ the control computer $e^{\prime}$, the information translation $\mathrm{C}$ - scanning by the laser $a^{\prime}$, we connect the elements of the structure $\mathrm{O}$ of the process equipment by the movements of the manipulator $b^{\prime}$ (Fig. 4, b), repeating all the connections indicated in [25] on the generalized diagram (Fig. 5, a). 


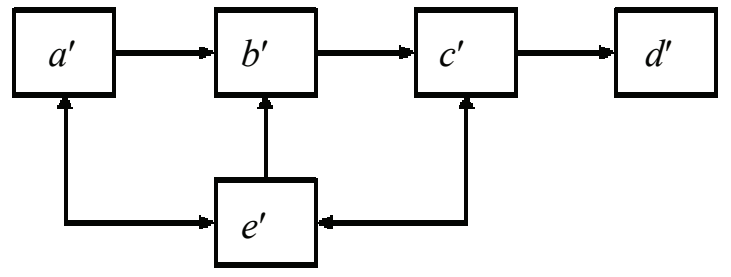

(a)

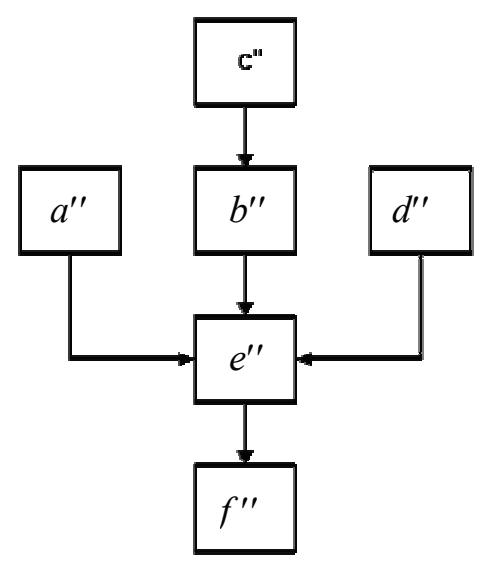

(b)

Fig. 5. Generalized diagrams of process equipment for the manufacture of parts by joining sheet materials $(a)$, sintering and fusion of powder layers $(b)$

From the algorithm for manufacturing parts from sheet materials (Fig. 4, $b$ ) obtained on the basis of the generalized diagram of the process equipment (Fig. 5, $a$ ), it can be seen that there are no operations 4 and $4^{\prime}$ connecting $c^{\prime}$ and $d^{\prime}$ with $a^{\prime}$, and the direction of connection 6 (Fig. 4, $a$ ) is reversed. Connection 4 of the press and the furnace $-c^{\prime}$ and $d^{\prime}$ with the cutting machine $a^{\prime}$ and feedback $4^{\prime}$ (Fig. $4, b$ ) will be required in the case when sheets of low-melting materials are connected to create a prototype or sheets of dissimilar materials, different by thickness and physical and mechanical properties. Such connections will provide a change in the intensity of radiation and will allow you to control the depth of cut and melting. In this case, for the press and the furnace $-c^{\prime}$ and $d^{\prime}$ earlier than the feedback, direct link 6 with the manipulator $b$ is required.

Thus, the study of the algorithm for manufacturing parts from sheet materials (Fig. 4, b) makes it possible to propose measures to expand the process capabilities of the equipment by creating layered parts from dissimilar materials.

\subsection{Sintering and fusion of powder layers (Rapid Prototyping)}

The process equipment for manufacturing parts by laser, electron-beam or other sintering and fusion of powder layers [29-31] contains the following main functional units (Fig. 5, b): a device for layer-bylayer powder feeding $a^{\prime \prime}$, a scanning device $b^{\prime \prime}$ of an emitting source $c^{\prime \prime}$, a device for layer-by-layer pressing of the powder $d^{\prime \prime}$ and a substrate $e^{\prime \prime}$ equipped with a vertical drive $f^{\prime \prime}$.

The analysis of the structure of links noted [25] in the generalized diagram (Fig. 5, b) demonstrates the correspondence of the devices for layer-by-layer feeding and pressing of the powder $a^{\prime \prime}$ and $d^{\prime \prime}$ - to the flows of matter and energy S, scanning device $b^{\prime \prime}$ and $c^{\prime \prime}$ - the software for reproducing B of the formed part, substrate $e^{\prime \prime}$, moved by the drive $f^{\prime \prime}$ - translation of information $\mathrm{C}$, which provides self-organization of the structure $\mathrm{O}$ of the process equipment (Fig. 4, c). The obtained algorithm for manufacturing parts by sintering and fusing powder layers (Fig. $4, c$ ) shows the presence of a minimum number of links between devices that ensure rapid prototyping of a model and production of a product. There are no operations 1, 5 and $1^{\prime}, 2^{\prime}$ associated with the prototyping software B (Fig. 4, a), operation 6, which ensures the connection of the vertical movement $f^{\prime \prime}$ of the formed part with the devices for layer-by-layer feeding and pressing of the powder $a^{\prime \prime}$ and $d^{\prime \prime}$, as well as feedback $4^{\prime}$ of the substrate $e^{\prime \prime}$ with $a^{\prime \prime}$ and $d^{\prime \prime}$.

Therefore, the process equipment must be supplemented with a system that controls beam scanning $b^{\prime \prime}$ and $c^{\prime \prime}$ [25], providing selective sintering and fusion of various layers of the powder by means of specified displacements and beam intensity. The use of the control system will make up for the missing connections in the structure of the algorithm (Fig. 4, $a$ ).

Thus, the study of the structure of links when obtaining parts by laser, electron beam or other sintering and fusion of powder layers (Fig. 4, c) indicates the need to use an additional control device for the part prototyping program.

As a result of the analysis of the methods of direct solid freeform fabrication of machine parts, the expediency of developing processes of laminate synthesis with controlled formation of material properties by energy flows is shown.

\section{Design of mechatronic process equipment in digital manufacturing}

Mechatronic systems include mechanical, electromechanical, electronic and control parts $[3,4$, $21,24,32,33]$. They include sensors of the state of the external environment and the control system itself; energy sources; executive mechanisms; amplifiers; computing elements (computers and microprocessors). 


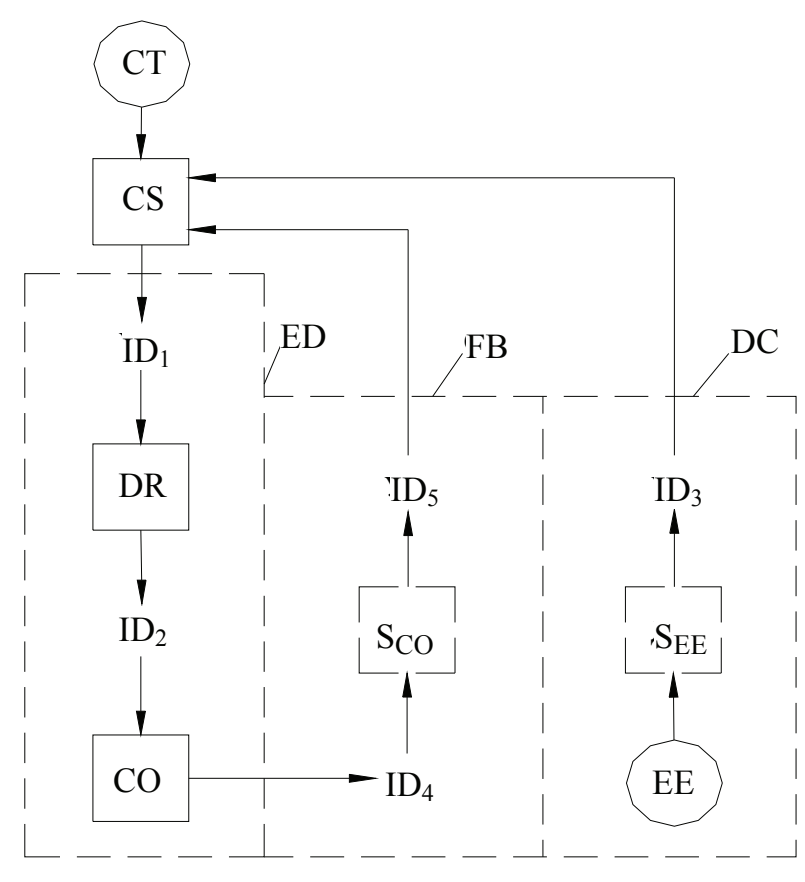

Fig. 6. Components of the mechatronic system of the technological complex:

ED - executive devices; FB - feedback; DC - direct connection; CT - control task; CS - control system; ID interface device; $\mathrm{DR}$ - drives; $\mathrm{CO}$ - control object; $\mathrm{S}_{\mathrm{CO}}-$ sensors of the state control object; $\mathrm{S}_{\mathrm{EE}}$ - sensors of the state of the external environment; EE - external environment

\subsection{Components of the mechatronic system}

A mechatronic system is a single set of electromechanical and electronic elements and computer facilities, between which there is a continuous exchange of energy and information. A functionally simple mechatronic system of a technological complex can be subdivided into the following components (Fig. 6): executive devices (control object and drives), information devices (sensors of the internal state of the system and sensors of the external environment) and a control system (computer and microprocessors).

The interaction between these parts, realizing direct connections and feedback in the system, is carried out through the interface device. The control system includes hardware and software that ensures the coordinated operation of the hardware and ensures synchronization of the processes of collecting and processing data from information devices with the processes that control actuators. As a result, the mechatronic production module for combined processing is structurally divided into electrical and mechanical components, as well as a control system.

\subsection{Structural diagram of the mechatronic system}

The generalized diagram of the production module of the process equipment (Fig. 7) must contain all the necessary components of the mechatronic

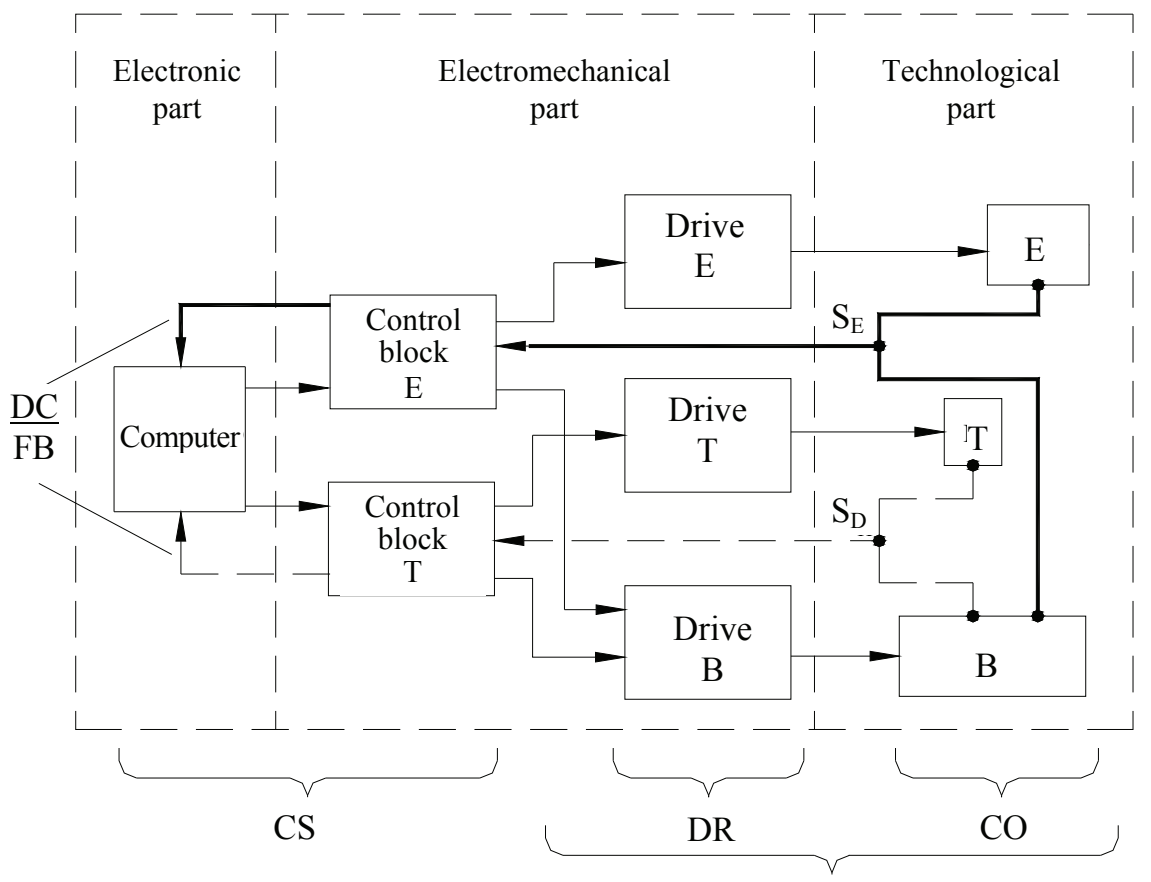

ED

Fig. 7. Structural diagram of the mechatronic system:

$\mathrm{B}$ - billet; $\mathrm{T}$ - tool; $\mathrm{E}$ - concentrated energy source; $\mathrm{S}_{\mathrm{D}}$ - displacement sensor; $\mathrm{S}_{\mathrm{E}}$ - energy flow intensity sensor; CS - control system; DR - drives; CO - control object; ED - executive devices; DC - direct connection; FB - feedback 
system: control objects; drives; sensors; control devices coupled to each other; software system.

The flexibility of the functioning of the mechatronic system in digitalized production is ensured by the use of universal working bodies capable of performing various operations (tools and energy sources), as well as by changing the modules of the replaceable tool, which are selected by the control system in accordance with the operations performed or the selection and management of energy sources.

In such process systems it is impossible to determine in advance the number and type of required actuators and sensors $[3,4,21,24,30,31]$. Therefore, it becomes necessary to solve two problems: 1) to process and systematize the information coming from the sensors; 2) to ensure synchronization between this information and the movement of the actuators.

This is achieved by software that controls the operation of the corresponding computing facilities. Consequently, algorithmic and software tools play a key role in ensuring the multifunctional operation of the mechatronic system. As a result, the structural diagram of any flexible production module using concentrated energy sources must have the considered elements in order to provide the module with a long time of stable operation in an autonomous mode using a minimum amount of control actions.

\section{Conclusion}

Thus, the analysis of the steps and stages of the design of process equipment for the production of traditional type and the study of the features of the formation of process equipment using flows of energy and consumables, the study of the structural synthesis of mechatronic complexes in digitalized production, made it possible to supplement the process of designing complexes of automated process equipment with new stages as for traditional subtractive and new additive manufacturing.

First of all, the design of mechatronic technological complexes in digitalized production, when creating a product, should be preceded by an analysis of information flows describing the movement of material and energy flows:

- from the working area of treatment with energy flows and the introduction of consumables in process equipment;

- through tools, equipment and drives of intensive treatment process equipment;

- to computers and their peripherals, access to local production and global networks of information resources.
Additional stages in the design of technological complexes include:

- first - the choice of energy sources and consumables for the intensification of processes with the analysis of the technological environment using flows of energy and material;

- then - the allocation of direct connections and feedback in a computerized process system under electro-physical-chemical and thermomechanical influences;

- in conclusion - the analysis of the adaptation processes of the equipment facilities in the manufacturing system, including the self-adjustment of the program and the self-organization of the structure of the automated equipment.

As a result of attracting additional design stages, based on tracing information flows, the following are produced:

- structural analysis of an open production system and synthesis of process equipment using energy sources and consumables;

- parametric optimization of modules and installations, tools and equipment for the process facility;

- layout of production modules and synthesis of an adaptive mechatronic system for highly efficient treatment.

\section{Funding}

The presented research is currently partly funded by grants for the Project 7.3.10 and others included the National Program of Scientific Research of the Republic of Belarus for 2021-2025 "Mechanics, metallurgy and technical diagnostics in mechanical engineering"; since 1999, it has been supported continually as part of the projects of the Belarusian Republican Foundation for Fundamental Research.

\section{Acknowledgments}

The author expresses gratitude to his numerous co-authors and colleagues, namely to his mentor, Academician of the National Academy of Sciences of Belarus P.I. Lashcheritsyn (Belarusian National Technical University) for giving support in the design of technological facilities for machine-building industry, Academicians of the National Academy of Sciences of Belarus P.A. Vityaz (United Institute of Mechanical Engineering of the National Academy of Sciences of Belarus) and S.A. Chizhik (A.V. Lykov Institute of Heat and Mass Transfer of the National Academy of Sciences of Belarus) for their contribution of ideas related to the problems under discussion and their assistance in developing a methodology for the design of equipment for nano- 
and additive technologies, and to Professor B.M. Bazrov (A.A. Blagonravov Institute of Mechanical Engineering RAS) for his ideas regarding the specifics of designing equipment on a modular basis for various types of industry and many others.

\section{Conflict of interests}

The authors declare no conflict of interest.

\section{References}

1. Yashcheritsyn PI, Kheifets ML, Kozhuro LM, Chemisov BP. Designing technological complexes of high-effective treatment of products on the basis of products multifactorial optimization. Doklady Natsional'noy akademii nauk Belarusi. 1997;41(3):112-118. (In Russ.)

2. Yashcheritsyn PI, Averchenkov VI, Kheifets ML, Kukhta SV. Analysis of the properties of ratios of technological solutions in designing combined methods of the treatment of materials. Doklady Natsional'noy akademii nauk Belarusi. 2001;45(3):106-109. (In Russ.)

3. Yashcheritsyn PI, Kheifets ML, Zeveleva EZ, Akulovich LM. Designing of mechatronic technological complexes of high-performance processing. Doklady Natsional'noy akademii nauk Belarusi. 2003;47(6):120-124. (In Russ.)

4. Rusetsky AM. Theoretical bases of technological systems designing. Minsk: Belaruskaya Nauka; 2012. 239 p. (In Russ.)

5. Vityaz PA, Kheifetz ML, Chizhik SA. "Industry 4.0": from information and communication and additive technologies to self-reproduction of machines and organisms. Vestsi Natsyyanal'noy akademii nauk Belarusi. Seriya fiziko-tekhnicheskikh nauk. 2017;2:54-72. (In Russ.)

6. Cherpakov BI. Metal-cutting machines and woodworking equipment; vol. IV-7. In: Frolov KV. (ed.) Mechanical engineering: Encyclopedia; Moscow: Mashinostroenie; 2002. 864 p. (In Russ.)

7. Pronikov AS, Averyanov OI, Apollonov YuS. Design of metal-cutting machine tools and machine-tool systems. Vol. 1. Machine tools design. Moscow: Mashinostroenie; 1994. 444 p. (In Russ.)

8. Vitiaz PA, Kheifetz ML, Koukhta SV. Laserplasma techniques in computer-controlled manufacturing. Minsk: Belorusskaya nauka; 2011. 164 p. (In Russ.)

9. Kheifets ML. Self-organization of structure formation processes in intense treatment and operation of materials. Advanced Materials and Technologies. 2016;3:14-20. DOI:10.17277/amt.2016.03.pp.014-020

10. Kheifetz ML. Self-organization of structure formation processes in intense treatment of materials. In: Dasic P. (ed.) Modern Manufacturing Process and
Systems; vol.1: Fundamentals. Collective monograph. Moscow-Belgrade-Vrnjacka Banja: SaTCIP Publisher Ltd.; 2018. p. 53-73. (In Russ.)

11. Kheifetz ML. From information and additive technologies to self-reproduction of machines and organisms. Advanced Materials and Technologies. 2018;1:22-35. DOI:10.17277/amt.2018.01.pp.022-035

12. Vityaz PA, Kheifetz ML, Chizhik SA Synergetic Technologies of Direct Layer Depositionin Aerospace Additive Manufacturing. In: Fores F, Boyer R. (eds.) Additive Manufacturing for the Aerospace Industry. Cambridge: Elsevier; 2019. p. 427-448.

13. Vasil'ev AS, Dal'sky AM, Klimenko SA, Polonsky LG, Kheifetz ML. Technological fundamentals of machine quality management. Moscow: Mashinostroenie; 2003. 256 p. (In Russ.)

14. Kheifetz ML. Design process of combined processing. Moscow: Mashinostroenie; 2005. 272 p. (In Russ.).

15. Bazrov BM. Modular technology in mechanical engineering. Moscow: Mashinostroenie; 2001. 368 p. (In Russ.).

16. Bazrov BM, Kheifetz ML. Method of presenting a product as an object of digitalization of manufacturing by a structured set of modules. Doklady Natsional'noy akademii nauk Belarusi. 2019;63(3):377-384. (In Russ.).

17. Artobolevskiy II, Il'inskiy DYa. Bases of the automatical systems of cars synthesis. Moscow: Mashinostroenie; 1983. 280 p. (In Russ.).

18. Vragov YuD. Analysis of configurations of metal-cutting machines: Komponetika bases. Moscow: Mashinostroenie; 1978. 208 p. (In Russ.)

19. Rusetsky AM (ed). Design and equipment of technological systems. Minsk: Belaruskaya Nauka; 2014. 316 p. (In Russ.)

20. Gordienko AI, Kozhuro LM, Kheifetz ML, Kukhta SV. Use of analogy parameters for development of combined physical-chemical material processing methods. Doklady Natsional'noy akademii nauk Belarusi. 2004;48(4):107-110. (In Russ.)

21. Rusetsky AM. Automation and control in technological complexes. Minsk: Belaruskaya Nauka; 2014. 375 p. (In Russ.)

22. Kheifets ML. Analysis of the algorithms of production of machine parts by models of von Neumann's self-reproduction. Doklady Natsional'noy akademii nauk Belarusi. 2001;45(5):119-122. (In Russ.)

23. Kheifetz ML. Formation of materials properties at the synthesis of layered components. Novopolotsk: Polotsk State University; 2001. 156 p. (In Russ.)

24. Kheifetz ML. Quality assurance of products in technological complexes. Minsk: Belaruskaya Navuka; 2019. 248 p. (In Russ.) 
25. Tolochko NK, Sobolenko NV, Mozsharov SE. Laminate synthesis technology - a new method of shaping powder products. Vestnik mashinostroyeniya $=$ Russian Engineering Research. 1995;4:22-25. (In Russ.)

26. Feygin M. Apparatus and method for forming an integral object from laminations. United States Patent 4,752,352. 21 June 1988.

27. Deckard CR. Method and apparatus for producing parts by selective sintering. United States Patent 4,863,538. 5 September 1989.

28. Beaman JJ, Deckard CR. Selective laser sintering with assisted powder handling. United States Patent 4,938,816. 3 July 1990.
29. Bourell DL, Marcus HL, Barlow JW, Beaman JJ, Deckard CR. Multiple material systems for selective beam sintering. United States Patent 4,944,817. 31 July 1990.

30. Kheifetz ML. Design of mechatronic technological complexes for traditional and additive manufacturing. Doklady Natsional'noy akademii nauk Belarusi. 2020;64(6):744-751. (In Russ.)

31. Chizhik SA, Kheifetz ML, Filatov SA. Prospects for the development of technological systems of composite materials additive synthesis and products shaping. Mekhanika mashin, mekhanizmov i materialov. 2014;4(29):68-74. (In Russ.)

\section{Информация об авторах / Information about the authors}

Хейфец Михаил Львович, доктор технических наук, профессор, директор, ГНУ Институт прикладной физики НАН Беларуси, Республика Беларусь, Минск; AuthorID (Scopus) 57214720034; e-mail:mlk-z@mail.ru
Mikhail L. Kheifetz, D. Sc. (Engineering), Professor, Director of Institute of Applied Physics of the National Academy of Sciences of Belarus; Minsk, Republic Belarus; AuthorID (Scopus) 57214720034; e-mail: mlk-z@mail.ru 